

\title{
Time-Resolved in Situ Raman and Small-Angle X-ray Diffraction Experiments: From Silica-Precursor Hydrolysis to Development of Mesoscopic Order in SBA-3 Surfactant-Templated Silica
}

Niki Baccile, Cilaine V. Teixeira, Heinz Amenitsch, Francoise Villain, Mika Lindén, Florence Babonneau

\section{To cite this version:}

Niki Baccile, Cilaine V. Teixeira, Heinz Amenitsch, Francoise Villain, Mika Lindén, et al.. TimeResolved in Situ Raman and Small-Angle X-ray Diffraction Experiments: From Silica-Precursor Hydrolysis to Development of Mesoscopic Order in SBA-3 Surfactant-Templated Silica. Chemistry of Materials, 2007, 20 (3), pp.1161-1172. 10.1021/cm702128u . hal-01457036

\section{HAL Id: hal-01457036 \\ https://hal.sorbonne-universite.fr/hal-01457036}

Submitted on 6 Feb 2017

HAL is a multi-disciplinary open access archive for the deposit and dissemination of scientific research documents, whether they are published or not. The documents may come from teaching and research institutions in France or abroad, or from public or private research centers.
L'archive ouverte pluridisciplinaire HAL, est destinée au dépôt et à la diffusion de documents scientifiques de niveau recherche, publiés ou non, émanant des établissements d'enseignement et de recherche français ou étrangers, des laboratoires publics ou privés. 


\section{Time-resolved in situ Raman and SAXS approach:}

\section{New insights in the formation mechanism of SBA-3}

\section{mesostructured silica powders from TEOS hydrolysis}

\section{to long-range order}

Niki Baccile ${ }^{1, \#}$, Cilaine V. Teixeira ${ }^{2, *}$, Heinz Amenitsch ${ }^{3}$, Françoise Villain $^{4}$,

\section{Mika Lindén ${ }^{2, *}$, Florence Babonneau ${ }^{1, *}$.}

${ }^{1}$ Laboratoire de Chimie de la Matière Condensée de Paris (LCMCP), Université Pierre et Marie Curie-Paris 6 CNRS, 4 place Jussieu, Paris, France

${ }^{2}$ Department of Physical Chemistry, Åbo Akademi University, Turku, Finland

${ }^{3}$ Institute of Biophysics and X-ray Structure Research, Austrian Academy of Sciences, Graz, Austria

${ }^{4}$ Chimie Inorganique et Matériaux Moléculaires (CIM2), Université Pierre et Marie Curie-Paris 6 CNRS, 4 place Jussieu, Paris, France

RECEIVED DATE (to be automatically inserted after your manuscript is accepted if required according to the journal that you are submitting your paper to)

\footnotetext{
\# Present address: Institut Charles Gerhardt Montpellier, CNRS/UM2/ENSCM/UM1, Montpellier, France

$¥$ Present address: Unitat de Biofisica, Facultat de Medicina, Universitat Autonoma de Barcelona, Spain

* Corresponding authors. e-mail: mlinden@abo.fi and fb@ccr.jussieu.fr
} 


\begin{abstract}
Word Style "BD_Abstract"). All manuscripts must be accompanied by an abstract. The abstract should briefly state the problem or purpose of the research, indicate the theoretical or experimental plan used, summarize the principal findings, and point out major conclusions. The optimal length is one paragraph.
\end{abstract}

KEYWORDS Mesostructured SBA-3, SAXS, Raman Spectroscopy, Time-resolved, In-situ, Formation mechanism

\title{
INTRODUCTION
}

Highly organized mesostructured silica based materials are, at present, a widespread research topic. Since their discovery in the 90 's, ${ }^{1,2}$ these materials have been largely studied mainly for their potential applications that rely on the possibility to prepare very high specific surface area powders with a range of chemical modifications on their exposed surface. Interests that they raised up were primarily focused on catalysis applications, and then extended to fields ranging from adsorption, sensing, encapsulation and even electronics. Several good quality reviews are available on this topic and we address the reader towards them for more details. ${ }^{3-4}$

Indeed, major advantages that supported research in the field are the mild conditions employed and the ease of synthesis steps. Nevertheless, the large number of works published on the topic has not entirely clarified yet all concerns about the mechanisms of formation, which involves several sequential and/or simultaneous events, occurring at different length scales: silica polycondensation process; interaction between amphiphilic moieties and inorganic species; development of micellar structure; long-range ordering; precipitation of final product with given shape and morphology.

Table 1 lists the characterization techniques that have been so far used in the literature to investigate the formation mechanisms of various silica-surfactant mesophases, with their main structural outputs. 
The molecular level is best characterized by spectroscopic techniques such as EPR, NMR, IR and Fluorescence, while SAXS together with TEM will specifically target the mesoscale.

Their performance for in-situ time resolved investigations has also been analyzed. They should allow to study in situ the reactive medium without any modification of the chemical composition and processing parameters. This is the key to ensure a good reliability to the proposed formation mechanism. We estimate that the system should be adapted as seldom as possible to the technique. This will be discussed more in details in the next paragraph. Their suitability as in-situ techniques was thus evaluated according to three criteria: a) Need to change the chemical composition of the starting system; b) Need to introduce extra entities required by the technique to be effective; c) Need to modify processing parameters such as type of the reaction container, stirring speed.... They should also ensure measurement times compatible with the kinetics of the events that one would like to follow. Real time tracking of the evolving system is preferred to punctual snapshots or to a response that has been averaged over a period of time during which the system undergoes many changes. The time-resolved efficiency was thus estimated from the characteristic measurement times associated to the technique. It is obvious that for fast reacting systems, the possibility to run time-resolved experiments will be more delicate than for slower evolving systems.

\section{Insert Table 1}

To complete this table, we would like to add some specific comments for each technique that have been suggested by analyzing in details the experimental conditions under which the so-called in-situ studies are performed.

TEM: transmission electron microscopy offers a very nice way to observe micelles, their shape evolution with time as well as their long-range arrangement to form mesostructures at different moments of the material synthesis. ${ }^{5}$ Specimen preparation is however a key issue to ensure observations representative of the solution structures. That is why cryo-TEM, a powerful tool for investigating nanostructures in soft materials, has also been used to investigate such silica/surfactant hybrid systems. ${ }^{6,7}$ Negative points concern the fact that TEM is not a truly in-situ approach since it only provides snapshots at chosen moments of reaction time; nevertheless, snapshots furnish quite a 
well representation of the reaction status at a given moment provided a quenching step in the synthesis procedure.

SAXS: small angle X-ray scattering is clearly the best technique to study short and long-range ordered micellar structures and shapes. Short acquisition times and adaptable experimental setup made it the most-used technique in time-resolved ${ }^{8-9}$ and even temperature-resolved ${ }^{10-11}$ in-situ experiments. Nevertheless, acquisition times obtained with low energetic X-ray sources are not compatible with time-resolved requirements, as it was already shown in 1998 by Lindén et al. ${ }^{12}$; hence, experiments must be performed in presence of high energetic X-ray source, like synchrotron radiation; this makes this type of experiments quite expensive and of difficult access. Energy Dispersion X-ray diffraction was used on SBA-1 materials ${ }^{13}$ but poor resolution does not give access to detailed mesophase parameters.

EPR: electron paramagnetic resonance is used to obtain information about the silica/micelle interactions during material formation. Such technique, extensively used by the groups of Goldfarb ${ }^{14}$ and Galarneau- Ottaviani, ${ }^{15}$ can be considered as being truly time-resolved due to its very high sensitivity even with a low amount of paramagnetic species. As far as in-situ approach is concerned, introduction of an external probe with a paramagnetic center brings an extra parameter to take into account. In addition, experimental synthesis conditions must be adapted to meet EPR apparatus requirements: use of either flat cells or tubes imply smaller reaction volumes where no stirring is available making this setup unsuitable for a number of established experiments. In some cases ${ }^{15}$, this aspect does not seem to really matter since stirring is replaced by temperature effect on material formation, as it occurs in material synthesis under hydrothermal conditions.

DLS: dynamic light scattering is seldom used to follow evolution of overall micellar size during self-assembly process, as ref. 16 and references therein put in evidence. Time-scale of DLS measures must be considered in the minute range (from 1 to 5) to obtain exploitable significant results. DLS was adapted to the in-situ approach but caution has to be taken since experiments take place in a smaller volume and stirring does not occur. In addition, solutions generally need dilution in order to increase reaction times and prevent powder precipitation in the very first minutes of reaction. 
Fluorescence: fluorescence technique is used to observe ion exchange mechanisms at the micellar/silica palisade in order to better understand organic/inorganic interactions. ${ }^{17}$ Even if timescale for signal detection is very fast, technique has some drawbacks as far as in-situ analysis is concerned: a well-chosen fluorescent probe must be introduced in the system while solution must be kept transparent at all times; finally, solution must be placed in a sample holder. Experiments proposed in ref. 17 were performed under $\mathrm{pH}$ conditions where no precipitation takes place.

NMR: Nuclear magnetic resonance is used in liquid state to reach a wide range of objectives depending on the nucleus under study. Unfortunately, it suffers from general drawbacks: 1) Confined volumes in NMR tubes do not permit stirring of the solution. 2) Precipitation should be avoided, which implies working with either slow reacting (e.g., Pluronic-structured materials) or modified systems (different $\mathrm{pH}$, dilution). 3) The low sensitivity for some nuclei requires isotopic enrichment that contributes to increase the overall cost and to introduce external species and/or synthetic steps. 4) Long relaxation times increase measurement times. However, NMR studies provided interesting results on various silica/surfactant systems:

- ${ }^{1} \mathrm{H}$ NMR was exploited by Flodström et al. ${ }^{18}$ to follow the decrease in line width of the signal from the methyl group of the PPO part of Pluronic F108 surfactant during the synthesis of a cubic Im3m silica/Pluronic mesophase. They attribute this behavior to lower mobility of PO group due to either large aggregates formation or interaction between Pluronic and growing silica. Study of protons gives quite reasonably short acquisition times letting time-resolved approach feasible.

- Quadrupolar nuclei like ${ }^{2} \mathrm{H}$ and ${ }^{14} \mathrm{~N}$ can be used to identify the surfactant mesophase geometry in presence of silicate species by looking at quadrupolar interaction parameters. Firouzi et al. ${ }^{19}$ used deuterium enriched quaternary ammonium salts while Egger et al. ${ }^{13}$ studied the ${ }^{14} \mathrm{~N}$ signal from the cationic surfactant polar head groups. Only drawback of ${ }^{2} \mathrm{H}$ is necessity of sample isotopic labeling.

- ${ }^{29} \mathrm{Si}$ can be used to follow hydrolysis-condensation of the silica precursors and formation of silica network in solution. This approach, which was tested, e.g., in ref. 13 and 19, is far from being timeresolved due to the low abundance, low sensibility and long relaxation times of ${ }^{29} \mathrm{Si}$ nucleus.

- ${ }^{17} \mathrm{O}$ was also used by Egger et al. ${ }^{13}$ to follow water reactivity and oxygen localization in quaternary ammonium salt structured silica. Here, prize to pay is necessary ${ }^{17} \mathrm{O}$ isotopic enrichment, 
and drastic decrease in the water content of the starting solution to minimize costs induced by the use of ${ }^{17} \mathrm{O}$-enriched water.

FT-IR: Infrared spectroscopy could be a perfect technique for time-resolved in-situ experiments due to its fast response time. Unfortunately, the strong adsorption of radiation by water in several regions of far and mid IR requires the use of sensitive attenuated total reflection (ATR) sampling devices, which are not compatible with true in situ measurements. Nevertheless, ATR-FTIR was effective to provide qualitative data regarding the species present during hydrolysis and condensation of TEOS under rich water conditions. ${ }^{20}$ The solvent spectra were subtracted from the sample spectra to better visualize the absorption bands for the species of interest. ATR-FTIR technique was also used to follow the synthesis of mesoporous silica in fatty acid/aminoalkoxysilane/water systems. ${ }^{21}$ Strong band overlap of the multiple species present in solution made however any quantitative analysis quite unreliable.

Raman spectroscopy: this technique can be used to follow inorganic precursor hydrolysis as a function of time. Time-resolved acquisitions are possible due to the fast response of Raman signal ${ }^{22}$ and new Raman spectrometers can be perfectly adapted to the set-up required for these experiments. The main positive point is the no-detection of the $\mathrm{HOH}$ angular deformation vibration band of water $^{23}$, but in all cases, non-fluorescing and limpid solutions are required. Raman was never adapted to time-resolved in-situ study of mesostructured silica materials.

Most of the in-situ mechanistic studies concentrated, so far, on one type of observations and correlations between them are difficult to establish because of the differences in chemical composition of the systems and experimental conditions. However, efforts have been recently made to combine complementary techniques, which allows to get a better overview of the formation process at various length scales: NMR was combined with $\mathrm{TEM}^{18}$ and also with $\mathrm{XRD}^{13}$, IR with $\mathrm{SAXS}^{21}$, and EPR with cryo-TEM ${ }^{24}$. As already pointed out in this last publication from the group of Goldfarb $^{24}$, it is important to carry out the experiments under the same reaction conditions to allow the correlation between the two length scales. It is also essential to avoid any major modification of the synthetic conditions, such as slowing down the reaction kinetics. Indeed, most of the studies 
combining various techniques have been performed on slow reacting systems for which measurement times in the order of minutes are compatible with the observed reaction kinetics. This is typically the case for the formation of SBA-15., ${ }^{9,25}$ For fast reacting systems involving, for example, cationic surfactants for which precipitation occurs within few minutes, the choice of time resolved in situ techniques is somehow limited.

Since the pioneer work of the researchers from Mobil ${ }^{1}$ mechanisms explaining the synthesis under basic conditions were proposed. None of them were based on in-situ measurements. The first proposition was based on the existence of a pre-formed liquid crystalline phase, which revealed to be a wrong guess, as shown by Chen et al. ${ }^{26}$, who used ${ }^{14} \mathrm{~N}$ NMR to prove that no hexagonal mesophase pre-exists in solution before addition of the silica source. The second proposition assumed a cooperation mechanism between preformed hexagonal micelles in solution and silicates, which eventually contributed to build up the long range ordered hexagonal mesostructure. Then, the charge density matching mechanism was proposed by the groups of Stucky and Chmelka. ${ }^{27,28}$ They explained that electrostatic interactions first occur between surfactant polar heads and multiple charged silicate oligomers in solution. Due to high surface charge density, the organic-inorganic mesophase formed from condensing silica species, has to pass through a low curvature lamellar phase before reaching the 2D-hexagonal phase, a higher curvature surface. This picture was similar to what Yanagisawa et al. ${ }^{29}$ already observed in 1990, when a progressive phase transformation from lamellar to hexagonal was observed in kanemite upon addition of long alkyl chain ammonium ion salts. Later in the $90 \mathrm{~s}$, several interesting studies put in evidence a self-assembling phenomenon between silicates and surfactant micelles and this was possible using in situ techniques, but after preventing the silicate species from extensive condensation. Firouzi et al. ${ }^{28}$ used NMR and neutron scattering techniques to show the formation of cylindrical micelles from spherical one upon silicate addition to the starting solution; Galarneau et al. ${ }^{15}$ used EPR in presence of well-chosen paramagnetic probes to prove that an exchange between silicate anions and surfactant counter-ion occurs at the micelle double layer interface while Frasch et al. ${ }^{17}$, by mean of fluorescent techniques showed that ion exchange is quite limited at the micellar double layer interface but it is rather enhanced when the surfactant molecule is alone in solution. Micelles only play a role of surfactant 
reservoirs rather than "building blocks" of the whole structure. It is important to repeat that these studies were only pursued on MCM-41-type materials, where direct electrostatic interaction occurs between negatively charged silica and positively charged ammonium surfactants.

On the contrary, literature is not as abundant on synthesis occurring under acidic conditions, as proposed by Huo et al., ${ }^{2}$ and leading to the formation of the SBA-1 (cubic Pm3n), SBA-2 (3Dhexagonal P63/mmc) and SBA-3 (2D-hexagonal, p6m) surfactant/silica mesophases. In this case, interactions between silica and surfactant are of different nature since a negative counter-ion (coming from the surfactant or from the acid used) interposes in between the positively charged micelles and the quasi-neutral silica surface. ${ }^{30}$ One can mainly cite the studies from Egger et al. ${ }^{13}$ who investigated the formation mechanism of the cubic Pm3n SBA-1 phase obtained from TEOS and CTEAB (cetyltriethylammonium bromide). They combined very nicely in situ EDXRD as well as multinuclear NMR $\left({ }^{29} \mathrm{Si},{ }^{17} \mathrm{O},{ }^{14} \mathrm{~N}\right)$ techniques; however, reactant molar ratios needed to be adapted to the employed techniques in order to optimize the experiments, and ended up to be quite far from the SBA-1 synthetic conditions. Lesaint et al. ${ }^{31}$ investigated the formation of the 2D-hexagonal SBA3 mesophase using DLS. However, as already mentioned for such technique, they had to dilute the system in a rather extensive manner compared to the original preparation from Huo $\left(\mathrm{H}_{2} \mathrm{O} / \mathrm{Si}=734\right.$ instead of 130), and the acid concentration was consequently lower (0.5-0.9 $\mathrm{M}$ instead of 3.9 M).

We thus decided to re-investigate the formation of SBA-3 in the same range of experimental conditions used by Huo et al. with cetyltrimetylammonium bromide (CTAB) as template, tetraethoxysilane (TEOS) as silica precusor and under highly acidic conditions. We wanted to combine techniques that could probe the molecular and the mesoscopic scale in real time on systems used to prepare well-ordered SBA-3 silica powders and for which precipitation occurs within few minutes. Looking at Table 1, Raman spectroscopy and SAXS seemed to be suitable ones. In particular, Raman spectroscopy is appropriate to follow the hydrolysis of TEOS, a fast reacting silica precursor, even if studies reported so $\operatorname{far}^{22}$ were performed in the absence of templating agents. Raman is not as powerful as ${ }^{29} \mathrm{Si}$ NMR to identify hydrolyzed and condensed species ${ }^{32}$, but its response time is fast enough to perform in situ time resolved study, which is absolutely impossible with ${ }^{29} \mathrm{Si}$ NMR. It is however clear that this technique will only be efficient prior to precipitation. 
We will show that it can be elegantly combined with SAXS experiments that will track the appearance and development of long-range order in various systems. A whole picture of the material synthesis can thus be obtained, starting from time $\mathrm{t}=0$ when the inorganic precursor is added to the surfactant solution, until the recover from solution of the precipitated silica-surfactant mesophase powder (Figure 1).

\section{EXPERIMENTAL SECTION}

Synthesis of silica based materials. All samples were prepared under acidic conditions using tetraethyl orthosilicate (TEOS, Aldrich), as the silica source and commercial CTAB (Aldrich) as structuring agent. Molar ratios between all reactants were adapted from original Huo's ${ }^{2}$ synthesis though several dilution conditions were tested as indicated in Table 2. The synthesis procedure is detailed elsewhere. ${ }^{30}$

\section{Insert Table 2}

Characterization. Raman effect was stimulated with a $750 \mathrm{~nm}$ laser (power: $150 \mathrm{~mW}$ ) connected to an optical fiber while the Raman emission was collected at $180^{\circ}$ with respect to the laser source. An optical lens system focalizes the light at the centre of the reaction beaker containing the CTAB aqueous solution. The solution was continuously stirred and the experiment was performed at room temperature. Time interval between data acquisition was set to $5 \mathrm{~s}$ and the experiment starts $(\mathrm{t}=0)$ when TEOS is added to the solution. Data were acquired and treated with HoloGRAMS ${ }^{\text {TM }}$ software package.

Small Angle X-ray Scattering (SAXS) experiments were conducted at Austrian SAXS beamline of the ELETTRA synchrotron laboratory in Trieste (Italy). ${ }^{33}$ The X-ray energy was $8 \mathrm{keV}(1.54 \AA)$ and the sample-detector distance was set to $955 \mathrm{~mm}$. A CCD camera (X-ray Imager, Photonic Sciences, Oxford, GB) was used as detector. The calibration was done with the silver behenate $(d=58.37 \AA)$. The framing rate was $10 \mathrm{~s} /$ frame with typical exposure times of $4 \mathrm{~s}$ for all experiments.

The reaction solution was circulated in a $1 \mathrm{~mm}$ quartz capillary using a batch reactor/flow through technique. ${ }^{8}$ The starting time $(\mathrm{t}=0 \mathrm{~s})$ was determined with adding TEOS to the batch reactor solution. All acquisitions were stopped after 25 minutes of stirring due to the fast meso-structuring process 
(from 3 to 5 minutes) except when powder aggregates form earlier and could cause clogging of the 1 mm quartz capillary. All 2D images have been corrected for detector artefacts (flat field, spatial corrections) and they have been integrated azimuthally by FIT2D. ${ }^{34}$ These 1D images obtained have been normalized for intensity fluctuations and the instrument background has been subtracted.

\section{Results and discussion}

TEOS hydrolysis kinetics. Time resolved in-situ Raman spectroscopy was used to follow the hydrolysis kinetics of TEOS in highly acidic aqueous $\mathrm{CTAB}$ solutions $\left(\mathrm{C}_{\mathrm{HCl}} \geq 2.5 \mathrm{M}\right)$ for three different compositions (Table 2).

The Raman spectra measured for $\mathrm{CTAB} / \mathrm{H}_{2} \mathrm{O} / \mathrm{HCl}$ and $\mathrm{CTAB} / \mathrm{EtOH} / \mathrm{H}_{2} \mathrm{O} / \mathrm{HCl}$ solutions with $\mathrm{C}_{\mathrm{HCl}}$ $=2.5 \mathrm{M}$ and $\mathrm{C}_{\mathrm{CTAB}}=3 \cdot 3 \cdot 10^{-2} \mathrm{M}$ are shown in Figure 2. The respective concentrations were chosen so that they correspond to the solvent composition of system B, assuming complete TEOS hydrolysis $(\mathrm{CTAB} / \mathrm{EtOH}=0.12: 4)$ for the second solution. The corresponding assignments of the Raman Stokes vibrations are given in Table $3{ }^{35-36-37} \mathrm{In}$ the absence of EtOH, the two most intense Raman bands of $\mathrm{CTAB}$ at 763 and $1063 \mathrm{~cm}^{-1}$, respectively assigned to $\mathrm{NCH}_{3}$ rocking mode from $\mathrm{N}^{+}\left(\mathrm{CH}_{3}\right)_{3}$ and $\mathrm{C}-\mathrm{C}$ stretching mode can be hardly detected due to the low CTAB concentration. ${ }^{38}$ In the presence of $\mathrm{EtOH}(\mathrm{CTAB} / \mathrm{EtOH}=0.12 / 4)$, three very strong peaks appear at 885, 1055 and $1095 \mathrm{~cm}^{-}$

1, assigned to $\delta\left(\mathrm{CH}_{\mathrm{x}}\right), v_{\mathrm{s}}(\mathrm{CO})$ and $v_{\mathrm{as}}(\mathrm{CO})$ vibrations respectively. ${ }^{37}$ The contribution to CTAB bands can thus be neglected in further analysis and this feature strictly depending on our synthesis protocol makes the whole Raman spectrum clearer and of much higher legibility.

\section{Insert Figure 2 and Table 3}

Time-resolved Raman spectra have been first recorded for a TEOS-containing solution in the absence (Figure 3a, 3b) of CTAB. Composition corresponds to system B (Table 2). An emulsion with rather large droplets remained all along the experiment. We should mention that stirring speed is a very important parameter that will influence the reaction kinetics in these systems. We maintained it constant within each set of experiments (around $300 \mathrm{rpm}$ ); however, from one set of experiments to another, it may have varied, changing the apparent kinetics. In Figure 3a, spectrum 1 is acquired 10 seconds after TEOS addition to solution. The two main bands at $658 \mathrm{~cm}^{-1}$ and 1095 
$\mathrm{cm}^{-1}$ assigned to $\operatorname{TEOS}^{37}$ are observed (Table 3). The spectral evolution with time shows the rapid decrease of the band at $658 \mathrm{~cm}^{-1}$ and the appearance of two new bands at $885 \mathrm{~cm}^{-1}$ and at $1055 \mathrm{~cm}^{-1}$ characteristic of the release of ethanol molecules produced by TEOS hydrolysis.

\section{Insert Figure 3}

The time-resolved integrated intensities of the TEOS band at $658 \mathrm{~cm}^{-1}$ and the ethanol band at 885 $\mathrm{cm}^{-1}$ are shown in Figure 3b. The amount of ethanol released during the reaction was quantified. The intensity of measured Raman scattering of a substance A can be analyzed according to equation $1: 39$

$$
\mathrm{I}(v)_{\mathrm{RA}}=\mathrm{K}(v)_{\mathrm{A}} \cdot \mathrm{V} \cdot \mathrm{C}_{\mathrm{A}} \cdot \mathrm{P}_{\mathrm{L}} \quad \text { Eq. } 1
$$

where $\mathrm{C}_{\mathrm{A}}$ is the concentration of $\mathrm{A}$ in solution, $\mathrm{V}$ is the volume of irradiated sample by light source, $\mathrm{P}_{\mathrm{L}}$ is the power density of laser and $\mathrm{K}(\mathrm{v})_{\mathrm{A}}$ is the absorption constant of substance A at irradiation frequency $v$. This linear relationship is valid when no other object scatters light and when the sample does not absorb or emit at the irradiation frequency. We consider fulfilling these conditions since the solution stays clear during the whole process for $t \leq 300 \mathrm{~s}$ with neither gelation, nor precipitation taking place. In addition, neither water nor TEOS and ethanol absorb or emit light at the irradiation frequency (here, $\lambda=750 \mathrm{~nm}$ ). Though we are unable to attribute absolute values to $\mathrm{V}$ and $\mathrm{P}_{\mathrm{L}}$, we can make the hypothesis that these parameters keep the same values from one solution to another if the experimental set-up is unchanged. If this condition is fulfilled, only the product $\mathrm{X}=$ $\mathrm{K}(v)_{A} \cdot V \cdot P_{L}$ has to be determined in order to calculate $C_{A}$ from measured intensity $\mathrm{I}(v)_{R A}$. In this work, measured intensity was related to ethanol concentration in water by mean of a calibration curve; experimentally $\mathrm{X}_{\mathrm{EtOH}}=6678 \pm 440$. We can then use this value to calculate $\mathrm{C}_{\mathrm{EtOH}}$ at any time during evolution. At $\mathrm{t}=300 \mathrm{~s}$, for instance, $\mathrm{C}_{\mathrm{EtOH}}{ }^{\exp }=0.96 \mathrm{M}$, which is comparable with the theoretical value, $\mathrm{C}_{\mathrm{EtOH}}{ }^{\text {th }}=1.10 \mathrm{M}$ that is expected if $4 \mathrm{EtOH}$ are produced per TEOS. Consequently, $\mathrm{t}=300 \mathrm{~s}$ is thus the minimum time needed for TEOS to fully hydrolyze under the employed experimental conditions and in absence of surfactant. Raman theoretical intensities corresponding to the release of 2, 3 or 4 ethanol molecules per TEOS are reported in Figure 3b. Interestingly, TEOS band vanishes after a reaction time of about 120 seconds when slightly more than 3 ethanol 
molecules have been produced. Indeed the band at $658 \mathrm{~cm}^{-1}$ only accounts for the symmetrical breathing mode of the $\mathrm{SiO}_{4}$ tetrahedra, which means that whenever one single -Si-OEt bond is hydrolyzed, this signal is no longer detected even if un-hydrolyzed Si-OEt bonds are still present. ${ }^{40}$ One would expect that when the overall TEOS signal is lost, the maximum ethanol concentration in solution could correspond to 1 molecule per silicon atom if at least one and only one -Si-OEt bond per TEOS is hydrolyzed. In reality, TEOS co-exists with species that have been submitted to multiple hydrolysis. This could be surprising since in excess of water, the concentration of Si-OEt groups was reported to rapidly tend to zero. ${ }^{41}$ Moreover, the hydrolysis rate depends strongly on the degree of substitution of the monomers, TEOS being the most reactive. But one should not forget that an emulsion remains all along the reactions, which may explain that TEOS molecules located in the core of the oil droplets have difficulty to be hydrolyzed, compared to $\mathrm{OH}$-substituted species which are located at the oil-water interface.

Bands for hydrolyzed monomers $\operatorname{Si}(\mathrm{OEt})_{4-\mathrm{x}}(\mathrm{OH})_{\mathrm{x}}$ have been reported $\mathrm{d}^{40,42}$ around 670 and $700 \mathrm{~cm}^{-1}$, which strongly overlap with the TEOS band resulting in the detection of only one broad band shifted to higher wavenumbers. Such a shift is not observed in Figure 3a, suggesting the absence of hydrolyzed monomers with sufficient lifetime to be detected. The formation of condensed species from $\mathrm{OH}$-substituted monomeric species could thus be anticipated. ${ }^{29} \mathrm{Si}$ NMR spectra and Raman spectra recorded on solutions with $\mathrm{H}_{2} \mathrm{O}$ :TEOS molar ratio between 0.5 and 1.75 and mild acidic conditions ( $\mathrm{HCl} 0.01-0.03 \mathrm{M}$ ) have been compared ${ }^{35,40}$; bands at $600,576,554,534 \mathrm{~cm}^{-1}$ have been assigned to dimers $\mathrm{Si}_{2} \mathrm{O}(\mathrm{OEt})_{6}$, linear trimers $\mathrm{Si}_{3} \mathrm{O}_{2}(\mathrm{OEt})_{8}$, linear and branched tetramers $\mathrm{Si}_{4} \mathrm{O}_{3}(\mathrm{OEt})_{10}$, respectively. These bands are of comparable intensity with respect to the TEOS band at $658 \mathrm{~cm}^{-1}$ except for the bands due to the tetramers that are much weaker. Hence, lack of detection of any band in the 500-600 $\mathrm{cm}^{-1}$ region indicates that few symmetric dimers and trimers are formed. Such species could have formed by condensation of monomeric species, $\mathrm{Si}(\mathrm{OEt})_{3}(\mathrm{OH})$, since TEOS reacts predominantly by water - producing condensation reactions. ${ }^{43} \mathrm{We}$ then assume that under our experimental conditions, species which are located at the surface of the TEOS droplets experienced multiple hydrolysis steps and subsequent condensation reactions forming oligomeric polysiloxanes, 
which are released in the aqueous phase, but can not be detected by Raman scattering, this technique being sensitive to symmetric vibrations of short-chain siloxanes.

Figure 3c shows the corresponding in situ time-resolved Raman experiments with CTAB present in the aqueous solution, which corresponds to system B (Table 2). First one should mention that in contrary to the previous case, an initial emulsion is formed with smaller and much more dispersed droplets, which disappears during the process. The same bands are detected due to TEOS and EtOH but the kinetics are different. The TEOS signal at $658 \mathrm{~cm}^{-1}$ rapidly decreases, and vanishes already at $\mathrm{t}=50 \mathrm{~s}$. Simultaneously, the peak due to $\mathrm{EtOH}$ at $885 \mathrm{~cm}^{-1}$ rapidly grows in intensity up to $90 \mathrm{~s}$, where it reaches an intensity value which corresponds to $\mathrm{C}_{\mathrm{EtOH}}{ }^{\exp }=0.95 \mathrm{M}$ indicative of complete TEOS hydrolysis. After $\mathrm{t}=90 \mathrm{~s}$, the intensity of the EtOH peak drops to zero within a 20 seconds time-span. As images of the reaction beakers show it in Figure 3d, powder precipitation does occur in solution at that point; scattering due to silica particles is too important and Raman signal is lost. When CTAB is added to solution, TEOS band disappears when about $2.5 \mathrm{EtOH}$ per TEOS are produced, which corresponds to a total degree of TEOS hydrolysis of $\sim 60 \%$. This is lower than for the CTAB-free system, for which the total degree of TEOS hydrolysis is $\sim 70 \%$. This tells us that the hydrolysis is more homogeneous in the presence of CTAB, and gives further support for the importance of solubilization/emulsion stabilization by CTAB. As already mentioned, in the absence of CTAB, a fair fraction of TEOS will not have hydrolyzed at all at intermediate times, while a many other TEOS molecules have gone through several hydrolysis steps within the same time.

An overall hydrolysis rate constant $k_{\mathrm{H}}$ can be introduced according to eq. (2) that corresponds to the averaging of the different hydrolysis reactions. ${ }^{44}$

$$
\equiv \mathrm{Si}-\mathrm{OEt}+\mathrm{H}_{2} \mathrm{O} \stackrel{k_{\mathrm{H}}}{\rightarrow} \equiv \mathrm{Si}-\mathrm{OH}+\mathrm{EtOH}
$$

with

$$
\mathrm{d}[\mathrm{Si}-\mathrm{OEt}] / \mathrm{d} t=-k_{\mathrm{H}}[\mathrm{Si}-\mathrm{OEt}]\left[\mathrm{H}_{2} \mathrm{O}\right]
$$

$$
[\mathrm{Si}-\mathrm{OEt}]_{t}=[\mathrm{Si}-\mathrm{OEt}]_{0} \cdot \exp \left(-k_{\mathrm{H}}\left[\mathrm{H}_{2} \mathrm{O}\right]_{0 . t}\right) \quad \text { eq. (4) }
$$

In our system, one can consider that the concentration of water remains constant. Eq. (3) thus gives : 
The evolutions of the concentration in Si-OEt species versus time, [Si-OEt $]_{t}$, can be obtained from the evolution of the concentration in EtOH in Figure $3 \mathrm{~b}$ and $3 \mathrm{c}\left([\mathrm{Si}-\mathrm{OEt}]_{t}=4[\mathrm{TEOS}]_{0}-[\mathrm{EtOH}]_{t}\right)$. The two resulting curves can be approximated with a monoexponential function according to eq (4). $\mathrm{k}_{\mathrm{H}} \approx 0.5 \mathrm{M}^{-1} \cdot \mathrm{h}^{-1}$ for the system without $\mathrm{CTAB}$ and $\mathrm{k}_{\mathrm{H}} \approx 1.0 \mathrm{M}^{-1} \cdot \mathrm{h}_{-}{ }^{1}$ for the system with CTAB. This analysis using a "global" hydrolysis rate is of course over simplified, but confirmed results reported in literature about a first-order kinetics for hydrolysis of TEOS in water-rich medium. ${ }^{20,41}$

In the same way, an overall rate constant can be defined for condensation reaction $k_{\mathrm{C} .}$.

$$
\begin{gathered}
k_{\mathrm{C}} \\
\equiv \mathrm{Si}-\mathrm{OH}+\mathrm{HO}-\mathrm{Si} \equiv \rightarrow \mathrm{Si}-\mathrm{O}-\mathrm{Si} \equiv+\mathrm{H}_{2} \mathrm{O}
\end{gathered}
$$

which indicates that in water-rich medium, condensation reactions between silanol groups is highly favored. Under such conditions, the rate of EtOH release should only depend on the hydrolysis reactions, and be independent from the initial concentration in TEOS [TEOS $]_{0}$. On the contrary, the condensation rate constant should depend on $[\text { TEOS }]_{0}$.

\section{Insert Figure 4}

For comparison purpose, a new set of experiments was performed with similar stirring conditions on the three systems A, B and C (Table 2). As shown in Figure 4, precipitation occurs in system A after about $\mathrm{t}=60 \mathrm{~s}$ though complete hydrolysis is not fully achieved, while in system $\mathrm{C}$ full hydrolysis is achieved about $110 \mathrm{~s}$ before precipitation takes place in solution. Interestingly, the rate at which $\mathrm{EtOH}$ is released is very similar for the three systems, confirming that dilution has little influence if any, on hydrolysis reactions ( $[\mathrm{Si}]=0.08 \mathrm{M}$ for system $\mathrm{C}$ and $0.43 \mathrm{M}$ for system $\mathrm{A}$ ). On the contrary, dilution plays a crucial role in the extent of TEOS condensation at the same acidic concentration $\left(\mathrm{C}_{\mathrm{HCl}}=3.9 \mathrm{M}\right)$ : the lower TEOS concentration in solution, the longer for powder precipitation to occur. In addition, one may observe that silica precursor and acid concentration both play an important role in TEOS and derived-oligomers reactivity, as shown by faster hydrolysis/condensation occurring in system A $\left(\mathrm{C}_{\mathrm{HCl}}=3.9 \mathrm{M}\right)$ with respect to system $\mathrm{B}\left(\mathrm{C}_{\mathrm{HCl}}=2.5\right.$ M). Effect of acidity on TEOS reactivity is a well-known result, as already discussed in ref. 20, 40. However, the presence of $\mathrm{CTAB}$ in the starting acidic solution plays a key role regarding the TEOS 
hydrolysis kinetics. The most plausible reason for the observed increase in the hydrolysis kinetics in the presence of $\mathrm{CTAB}$ is the possibility for TEOS solubilization within micelles and/or kinetically stabilized emulsion droplets, which increases the surface/volume ratio of the TEOS droplets, enhances the TEOS-water contact, and thus leads to a higher TEOS hydrolysis rate. Hydrodynamic effects, related to the stirring speed, have previously been shown to have a pronounced influence on the hydrolysis kinetics of TEOS under alkaline conditions. ${ }^{45}$ The importance of solubilization effects is highlighted by the fact that the observed hydrolysis kinetics is proportional to the CTAB concentration in the sol, and the solubilization power of CTAB calculated per molecule should increase when the $\mathrm{CTAB}$ concentration is higher than the critical micelle concentration, $\mathrm{CMC}$. The high ionic strength of the sol due to the high concentrations in $\mathrm{HCl}$ should serve to further enhance the solubilization capacity of $\mathrm{CTAB}$, as the repulsive charges between the surfactant head-groups in a surfactant aggregates would be effectively screened, which serves to stabilize surfactant aggregate of lower curvature. The influence of CTAB on the hydrolysis kinetics is then supposed to be the highest at the early stages of the reaction, as TEOS is a very hydrophobic molecule and it will be solubilized inside the interior of the micelles. As the hydrolysis proceeds, the water solubility of these partially hydrolyzed TEOS molecules will increase, and thus the preference for solubilization within surfactant aggregates is lower, and further hydrolysis can occur outside the micellar aggregates.

In-situ SAXS experiments. Time-resolved in-situ SAXS experiments were used to follow the mesophase evolution. The experimental conditions were similar to those used for the Raman experiments shown in Figure 4. Time-resolved XRD patterns for systems A-C are shown in Figure 5, and surface plots of the same measurements are shown in Figure 6. The time at which the (10) reflection of the $2 \mathrm{D}$ hexagonal mesophase appears in the different cases is strongly system dependent, and it follows the order of TEOS-CTAB concentrations in the sols. For the most concentrated system, A, the (10) reflection is seen already after a reaction time of about $50 \mathrm{~s}$, which corresponds to a total TEOS hydrolysis degree of about 60\% (Figure 4), and this time is in good agreement with the time at which the solutions became turbid in the Raman experiments. For system 
$\mathrm{B}$, the (10) reflection is visible about $80 \mathrm{~s}$ into the reaction, which corresponds to a TEOS hydrolysis degree of about $90 \%$. For the most dilute system, system $\mathrm{C}$, the first sign of a 10 reflection is seen after a reaction time of about $250 \mathrm{~s}$, while complete hydrolysis of the TEOS has been reached already in less than 200 s. Taking the concentration differences in the different systems into account, (the TEOS concentrations in the starting sols have the approximate ratios 5.4:3.5:1 for system A:system B:system C) one can observe that the total hydrolysis extent at which some degree of order is observed in the diffractograms are similar for systems A and B, while the kinetics of formation of an ordered silicate-surfactant phase occurs at a lower total concentration of hydrolyzed TEOS in the sol for system C. As the TEOS hydrolysis kinetics was found to be strongly dependent on the stirring rate, the phase separation kinetics was also followed by a video camera, and the time at which the first signs of a Bragg reflection (10) appears in the respective diffractograms corresponds to the time at which the sol turns milky. This allows us to establish a direct link between the Raman measurements and the SAXS measurements, although the stirring rates may be slightly different in the two sets of experiments. For system A, the (11) and (20) reflections appear virtually at the same point in time, while the (20) reflection appears before the (11) reflection for systems B and C. This suggests that the silica wall thickness is larger for system B than for system A,as the Fourier phasing was found to be -++ for the 10,11 , and 20 reflections, similar to what has been observed for MCM $-41^{45}$ (results not shown). While the high order reflections appear just after the appearance of the (10) reflection in system $\mathrm{A}$, there was a time difference of about $50 \mathrm{~s}$ for system $\mathrm{B}$, and $150 \mathrm{~s}$ for system C. In addition to the (10), (11), and (20) reflections characteristic of a $2 \mathrm{D}$ hexagonal mesophase, an additional broad reflection of low intensity at lower angles (q about 0.8 (FB:1.1?) $\mathrm{nm}^{-}$ $\left.{ }^{1}\right)$ can be observed both in Figure 5c and Figure 6c after a reaction time of $800 \mathrm{~s}$. The origin of the reflection is not known, but could indicate the presence of another co-existing phase of low concentration and mesoscopic order.

The positions of the main (10) reflection are plotted as a function of time for the different systems in Figure 7 The most striking observation is that the d-spacing of the $2 \mathrm{D}$ hexagonal phase is generally lower the lower the TEOS/CTAB concentration was in the starting sol at any given reaction time. The positions of the (10) reflection at the time of its first appearance are $4.22 \mathrm{~nm}, 4.29$ 
$\mathrm{nm}$, and $4.31 \mathrm{~nm}$ for systems A, B, and C, respectively. Furthermore, the d-spacing decreases with reaction time in all systems, at a rate which is proportional to the TEOS/CTAB concentration. Two distinctively different stages in the decrease in the d-spacing with time can be observed, the kinetics of which are also strongly dependent on the sol composition. A fairly fast decrease in the d-spacing is observed in all cases up to a reaction time of about $500 \mathrm{~s}$ for systems $\mathrm{A}$ and $\mathrm{B}$, followed by a second stage of slower but almost linear decrease. For system $\mathrm{C}$, on the other hand, the position of the (10) reflection remains virtually constant during the time of observation. The time at which the second stage is reached is strongly concentration dependent, and it is observed after a reaction time of about $500 \mathrm{~s}$ for system A, about $1400 \mathrm{~s}$ for system B and C, although for system $\mathrm{C}$ the decrease is not as evident as for system B. (See also the evolution of the position of the high order reflections with time in Figure 6). At the intermediate plateau, the corresponding distances are $4.12 \mathrm{~nm}$, and $4.24 \mathrm{~nm}$ for systems A and B, respectively, (calculated directly as $\mathrm{d}=1 / \mathrm{s}$ ) which indicates an only marginal decrease in the repeat distance during the first phase. We note that this small decrease in the unit cell dimensions can not be connected to a decrease in the micellar diameters due to release of hydrolyzing TEOS from the interior of the micelles, as the decrease in unit cell dimension occurs at times well past that needed for complete hydrolysis of TEOS in system B. At a reaction time of $2000 \mathrm{~s}$, i.e. well within the second stage of the process, the corresponding values are $4.03 \mathrm{~nm}$ and $4.17 \mathrm{~nm}$ for system $\mathrm{A}$ and $\mathrm{B}$, which translates to a unit cell size of $4.65 \mathrm{~nm}$ and $4.81 \mathrm{~nm}$, respectively. Thus, the repeat distances in the silicate-surfactant phase at any point in time follow the order of TEOS/CTAB concentration in the initial sol; the higher the initial TEOS/CTAB concentration, the smaller the repeat distance. This is also observed for the as-synthesized and dried materials isolated after a complete synthesis (time $=300 \mathrm{~min}$.$) , for which the \mathrm{d}$-spacings are $3.71 \mathrm{~nm}$, $3.82 \mathrm{~nm}$, and $3.87 \mathrm{~nm}$, for materials synthesized according to procedure $\mathrm{A}, \mathrm{B}$, and $\mathrm{C}$, respectively (results not shown).

The integrated intensities of the (10) reflection are plotted as a function of time in Figure 8. For all systems, an exponential increase in the integrated intensity is observed during the time window corresponding to the first stage of the decrease in the d-spacing shown in Figure 7. The rate at which the intensity increases during this stage is following the order system $\mathrm{A}>$ system $\mathrm{B}>$ 
system $\mathrm{C}$, i.e. the order of increasing TEOS/CTAB concentration in the starting sol. For systems B and $\mathrm{C}$, the intensity then reached a plateau, while the intensity increases almost linearly at reaction times corresponding to the second stage of the decrease in the d-spacing shown in Figure 7. Furthermore, it is interesting to note, that the ratio of the integrated intensities after the first stage, i.e. after a reaction time of $500 \mathrm{~s}$ (system A), $1000 \mathrm{~s}$ (system B), and $1500 \mathrm{~s}$ (system C), follows virtually exactly the corresponding ratios of the initial CTAB/TEOS concentrations in the different sols. This suggests that the amount of phase-separated silicate-surfactant is virtually the same in all cases, if normalized against the initial concentrations of CTAB and TEOS.

Finally, the evolutions of the full-width-at-half-maximum, FWHM, of the respective (10) reflections are shown in Figure 9. The FWHM values are normalized against the position of the (10) reflection in order to be able to directly compare the different FWHM values with each other. There is a huge difference in the values, with system A initially having by far the largest FWHM values followed by system B. The normalized FWHM values of system C are more than 4 times lower than those observed for systems A and B. Generally, a pronounced increase in the normalized FWHM values are observed after the $2 \mathrm{D}$ hexagonal mesophase has formed, and this effect follows the order system $\mathrm{C}<$ system $\mathrm{B}<$ system A. For systems A and B, a slow decrease in the normalized FWHM values is observed at times corresponding to the initiation of the second reaction stage observed in the d-spacing vs. time plots, corresponding to a reaction time of about $500 \mathrm{~s}$ for system $\mathrm{A}$, and about $1400 \mathrm{~s}$ for system B.

\section{General mechanistic discussion}

Generally seen, our data is in full agreement with the common understanding that the formation of silicate-CTAB mesophases in dilute sols using alkoxides as the precursor for silica involves the following steps: 1) Hydrolysis of the silica precursor followed by condensation leading to the formation of oligomeric siliceous species. Here the hydrolysis kinetics of the silicon alkoxide is highly enhanced in the presence of the surfactant due to micellar solubilization and surfactant stabilization of emulsion droplets, 2) Phase separation into one phase rich in silicate and surfactant and another solvent-rich phase, 3) Nucleation and growth of a surfactant-silica mesophase in this 
concentrated phase. The different reaction steps can be partly overlapping. However, according to the fact that we carried out the measurements under different degrees of dilution, and also measured the extent of TEOS hydrolysis as a function of time, we can draw some more conclusions about the chemical events leading to the formation of the 2D hexagonal phase, and the influence of their relative rates.

From our data it is clear that the time at which phase-separation occurs is not related to the relative extent of TEOS hydrolysis, but to the absolute concentration of hydrolyzed species, as indicated by the observed kinetics in systems A and B. However, this is not the whole truth, as phase-separation occurs at absolute concentration of hydrolyzed TEOS, which is lower than those in systems A and B. (FB:??) Our results thus indicate that the condensation kinetics is also a crucial parameter in the formation of SBA-3, and that a certain level of silicate condensation has to be reached before phase-separation occurs. It is plausible that the first step observed in the s-spacing versus time plots is connected to the correlation distance in the phase separated silicate and surfactant phase, and that the nucleation and growth of the 2D hexagonal phase is very fast within this phase. The low micellar scattering intensity does not allow us to determine the shape of the micelles in the phase-separated silicate-surfactant phase, but one can assume that cylindrical micelles are present due to the short correlation distance observed, meaning the silicate-surfactant phase is fairly concentrated. The single (10) reflection observed for different times in the different systems before the high order reflections appear is normally observed for wormhole-like materials, which are formed from entangled micelles. However, we note that a single reflection has also recently been observed for mesoscopic silicate-CTAC nanoparticles synthesized under alkaline conditions with a larger repeat distance than what would be normally observed for 2D hexagonally ordered MCM-41 type materials. ${ }^{46}$ In a recent study on MCM-41, local differences in the degree of silicate condensation was suggested to be present within growing domains with hexagonal order, based on detailed analysis of the time-dependent full-with-at-half-maximum of the reflections. It was suggested, based on earlier TEM studies, ${ }^{47}$, that the cylinders inside the domains are more tightly packed during the stages where the silicate condensation reactions are still on-going, as compared to the rim of the particle facing the solution. The formation of larger aggregates that dry/condense faster 
in more concentrated sols, would work in the direction of a tighter micellar packing at least during the early stages of the formation process. This would explain the differences in the repeat distances observed between the studied systems, and it would also explain why system $\mathrm{C}$ does not reach the second stage of the process, where the 2D hexagonal phase nucleates and grows despite the fact that the local concentration of silicate-and surfactant is high, but the particle size may still be very small during the initial stages of the process, leading to a slower particle growth by aggregation. Actually, in a recent study domain growth by particle fusion was observed under alkaline conditions (MCM-41 type materials) ${ }^{46}$ which would be another process strongly bound to particle concentration, which again could explain the slow kinetics of mesophase nucleation and growth in system $\mathrm{C}$ as compared to systems A and B. This view is supported by the development of the unit cell dimensions obtained for the three studied systems, and also by the increase in the FWHM values when the hexagonal phase appears. However, the evolution of the normalized FWHM values of the 10 reflection with time is very different as compared to that observed during the formation of MCM-41 at a $\mathrm{pH}$ of 10.8. ${ }^{45}$ Here, the normalized FWHM of the (10) reflection decreases very soon after the 2D hexagonal phase appears, and remains virtually constant during the observation time. A similar evolution of the FWHM of the main reflection has also been observed for SBA-15, which is synthesized under acidic conditions using non-ionic tri-block co-polymers as the structure directing agent. ${ }^{9}$ The normalized FWHM values of the (20) reflection of MCM-41 follows a similar evolution in time as observed for the (10) reflection in the present study, where the FWHM values initially increase, followed by a second phase of slow decrease. This very different behavior for MCM-41 and SBA-3 tells that the relative rates of the kinetic events leading to the formation of the fully developed mesophase are different in the two cases. For MCM-41, the FWHM evolution is suggesting that the mesophase formation involves a stage of second order disorder, which is compatible with a difference in the rate of silicate condensation within formed aggregates, which also can be a function of size of the ordered domains. ${ }^{45-46-47}$ For SBA-3, the time-evolution of the FWHM seems to be controlled by a combination of several effects; an increase of the dispersion of d-spacings originating from the nucleation of a hexagonally order phase together with a co-existing less-ordered phase over extended periods of time, and an increasing FWHM in systems where the nucleation and growth of 
the hexagonal phase occurs before full hydrolysis of TEOS. When the hexagonal phase continues to grow, the FWHM values gradually decreases again. The most homogeneous nucleation and growth, but also the slowest growth kinetics, was observed for the most dilute system, system $\mathrm{C}$, which had hydrolyzed completely before the phase-separation into the silicate-surfactant rich phase occurred. The more dilute the sol, the slower should the particle-particle aggregation process be as well, which is another important step in the mesophase formation. The evolutions of the FWHM of the systems A and B also suggest that the particle-particle aggregation kinetics also play an important role, as has already been observed for MCM-41, ${ }^{45-46}$ as particle-particle aggregation can lead to a faster drying of the particles due to a decreased particle-water contact area. ${ }^{47}$ This process should be accompanied by a faster condensation kinetics in the hexagonally ordered phase, which is supported both by the lower d-spacings observed at higher CTAB/TEOS concentrations, as well as by the fact that the intensity ratio of the (11) to (20) reflection increases more pronounced for the slower reacting systems B and $\mathrm{C}$, and by the initial absence of the (11) reflection. Such a behavior of the $(11) /(20)$ intensity ratio is compatible with an increase in the silicate layer thickness in comparison to the radius of the micelles for systems having a Fourier phasing of $-++{ }^{45}$ Furthermore, the absence of the (11) reflection at the initial stages for systems B and C suggests that these systems are at the borderline between Fourier phases - + + , observed for MCM-41, ${ }^{45}$ and - - +, observed for SBA- $15,{ }^{9}$ which is another indication for a thicker silicate walls in systems B and C as compared to system A. Thus, our results suggest that the silicate layer thickness is initially larger at lower TEOS/CTAB concentrations. Furthermore, differences in the relative rates of domain growth of the $2 \mathrm{D}$ hexagonally order portions versus particle-particle aggregation may also contribute to the observed differences in the FWHM values between the systems. A fast particle-particle aggregation as compared to the domain growth rate may induce disorder if oriented attachment effects are not prevalent. Finally, we note that although the phase separation kinetics in the studied systems are compatible with that of MCM-41 synthesized using ammonia as the catalyst, the growth kinetics of the mesophase is slower, which can be ascribed to a slower overall silicate condensation rate under the studied conditions for the SBA-3 system as compared to MCM-41 synthesized in the presence of ammonia, and that the overall ordering kinetics is slower. In this respect, also the absence of strong electrostatic interactions between the positively 
charged structure directing agent and the silicate species under acidic conditions, where the silicate species carry a close to neutral or slightly positive charge, may influence the silicate condensation kinetics in the mesophase. Under alkaline conditions, where the silicate species carry a negative charge, the formation of cylindrical micelles should be faster as compared to under acidic conditions, as surfactant charge neutralization favors the transition from spherical to cylindrical micelles, ${ }^{48}$ which should increase the rate of ordering in the mesophase.

\section{Conclusion}

This work deals with a complete time-resolved in-situ study of CTAB templated silica under highly acidic conditions. We meant to follow the silica precursor reaction kinetics as well as material ordering with time. Raman spectroscopy was employed here for the first time to follow TEOS reactivity in water under unmodified synthesis conditions. Hydrolysis reaction occurs 3 times faster when CTAB is added to solution and we have explained this behaviour to smaller size of TEOS droplets in water, that is to the highest exposed TEOS area. After excluding several hypotheses, we think that either micelles or free surfactant molecules might disperse TEOS emulsion. Both of them might be consistent with known literature data and with SAXS experiments that are presented here. In fact, once Raman spectroscopy ceased to be useful, at $140 \mathrm{~s}$ from TEOS addition when a precipitate forms in solution, SAXS data started to show the beginning of a mesophase formation within the observed precipitate. A correlation distance appears directly and it evolves into a 2Dhexagonal mesophase, the one observed in final material. ED calculations of SAXS patterns at different reaction times show the direct image of the micelles within the material as well as the evolution with time of silica condensation. It is clear that at early stage of reaction, inter-micellar condensation is mostly observed while intra-micellar condensation only takes place with time. This behaviour is opposite to what it was observed in SBA-15 materials. 


\section{References}

(1) Beck, J.S.; Vartuli, J.C.; Roth, W.J.; Leonowicz, M.E.; Kresge, C.T.; Schmitt, K.D.; Chu, C.T.W.; Olson, D.H.; Sheppard, E.W. J. Am. Chem. Soc., 1992, 114, 10834.

(2) Huo, Q.; Margolese, D.I; Ciesla, U.; Feng, P.; Gier, T.E.; Sieger, P.; Leon, R.; Petroff, P.M.; Schüth, F.; Stucky, G.D. Nature, 1994, 368, 317.

(3) Soler-Illia, G. J.d.A.A.; Sanchez, C.; Lebeau, B.; Patarin, J. Chem. Rev., 2002, 102, 4093.

(4) Patarin, J.; Lebeau, B.; Zana, R. Curr. Op. Coll. Interf. Sci., 2002, 7, 107.

(5) Díaz, I.; Alfredsson, V.; Sakamoto, Y. Curr. Op. Coll. Interf. Sci., 2006, 11, 30.

(6) Regev, O. Langmuir, 1996, 12, 4940.

(7) Ruthstein, S.; Schmidt, J.; Kesselman, E.; Talmon, Y.; Goldfarb, D. J. Am. Chem. Soc., 2006, $128,3366$.

(8) Ågren, P. ; Lindén, M.; Rosenholm, J.B.; Schwarzenbacher, R.; Kriechbaum, M.; Amenitsch, H.; Laggner, P.; Blanchard, J.; Schüth, F. J. Phys. Chem. B, 1999, 103, 5943.

(9) Flodström, K.; Teixeira, V.T.; Amenitsch, H.; Alfredsson, V., Lindén M., Langmuir, 2004, 20, 4885.

(10) Gross, A.F.; Ruiz, E.J.; Tolbert, S.H. J. Phys. Chem. B, 2000, 104, 5448.

(11) Tolbert, S.H.; Landry, C.C.; Stucky, G. D.; Chmelka, B. F.; Norby, P.; Hanson, J. C.; Monnier, A. Chem. Mater., 2001, 13, 2247.

(12) Lindén, M.; Schunk, S.A.; Schüth, F. Angew. Chem., Int. Ed., 1998, 37, 821.

(13) Egger, C.C.; Anderson, M.W.; Tiddy, G. J. T.; Casci, J.L Phys. Chem. Chem. Phys., 2005, 7, 1845. 
(14) Zhang, J.; Luz, Z.; Goldfarb, D. J. Phys. Chem. B, 1997, 1001, 7087.

(15) Galarneau, A.; di Renzo, F.; Fajula, F.; Mollo, L.; Fubini, B.; Ottaviani, M.F. J. Coll. Interf. Sci., 1998, 201, 105.

(16) Mesa, M.; Sierra, L.; Guth, J.-L. Micro. Meso. Mater., 2007, 102, 70.

(17) Frasch, J.; Lebeau, B.; Soulard, M.; Patarin, J.; Zana, R. Langmuir, 2000, 16, 9049.

(18) Flodström, K.; Wennerström, H.; Alfredsson, V.; Langmuir, 2004, 20, 680.

(19) Firouzi, A.; Atef, F.; Oertli, A.G.; Stucky, G.D.; Chmelka, B.F. J. Am. Chem. Soc., 1997, 119, 3596.

(20) Tejedor-Tejedor, M. I.; Paredes, L.; Anderson, M.A. Chem. Mater., 1998, 10, 3410.

(21) Rodriguez-Abreu, C.; Izawa, T.; Aramaki, K.; Lopez-Quintela, A.; Sakamoto, K.; Kunieda, H. J. Phys. Chem. B, 2004, 108, 20083

(22) Marino, I.-G.; Lottici, P.P.; Bersani D.; Raschella', R.; Lorenzi, A.; Montenero, A. J. NonCryst. Sol., 2005, 351, 495.

(23) Rull, F. Pure Appl. Chem., 2002, 74, 1859.

(24) Ruthstein, S.; Schmidt, J.; Kesselman, E.; Talmon, Y.; Goldfarb, D.; J. Amer. Chem. Soc., 2006, 128,3366 .

(25) Khodakov, A.K.; Zholobenko, V.L.; Impéror-Clerc, M.; Durand, D. J. Phys. Chem. B, 2004, $109,22780$.

(26) Chen, C-Y.; Burkett, S.L.; Li, H-X.; Davis, M.E. Micro. Mater, 1993, 2, 27.

(27) Monnier, A.; Schüth, F.; Huo, Q.; Kumar, D.; Margolese, D.; Maxwell, R.S.; Stucky, G.D.; Krishnamurty, M.; Petroff, P.; Firouzi, A.; Janicke, M.; Chmelka, B.F. Science, 1993, 261, 1299. 
(28) Firouzi, A.; Kumar, D.; Bull, L.M.; Besier, T.; Sieger, P.; Huo, Q.; Walker, S.A.; Zasadzwinski, J.A.; Gluka, C.; Nicol, J.; Margolese, D.I.; Stucky, G.D.; Chmelka, B.F. Science, 1995, 267, 1138.

(29) Yanagisawa, T.; Shimizu, T.; Kuroda, K.; Kato, C. Bull. Chem. Soc. Jap., 1990, 63, 988.

(30) Baccile, N.; Laurent, G.; Bonhomme, C.; Innocenzi, P.; Babonneau, F. Chem. Mater., 2007, $19,1343$.

(31) Lesaint, C.; Lebeau, B.; Marichal, C.; Patarin, J.; Zana, R. Langmuir, 2005, 21, 8923.

(32) Artaki, I.; Bradley, M.; Zerda, T.W.; Jonas, J. J. Phys. Chem., 1985, 89, 4399.

(33) Amenitsch, H.; Rappolt, M.; Kriechbaum, M.; Mio, H.; Laggner, P.; Bernstorff. S. J Synchrotron Rad. 1998, 5, 506.

(34) http://www.esrf.eu/computing/scientific/FIT2D/

(35) Gnado, J.; Dhamelincourt, P.; Pélégris, C.; Traisnel, M.; Le Maguer Mayot, A. J. Non-Cryst. Sol., 1996, 208, 247.

(36) Lippert, J.L.; Melpolder S.B.; Kelts L.M., J. Non-Cryst. Sol., 1988, 104, 139.

(37) Matos M.C.; Ilharco L.M.; Almeida R.M., J. Non-Cryst. Sol., 1992, 147\&148, 232.

(38) Kalyanasundaram, K.; Thomas; J.K. J. Phys. Chem., 1976, 80, 1462.

(39) Aarnoutse, P.J.; Westerhuis, J.A. Anal. Chem., 2005, 77, 1228.

(40) Mulder, C. A. M.; Damen, A. A. J. M. J. Non-Cryst. Sol., 1987, 93, 169.

(41) Pouxviel, J.C.; Boilot, J.P.; Beloeil, J.C.; Lallemand, J.Y. J. Non-Cryst. Sol., 89, 1987, 345.

(42) Barrie, J.D.; Aitchison, K.A.; Mat. Res. Soc. Symp. Proc.1992, 271, 225.

(43) Assink, R.A.; Kay, B.D. Coll. Surf. A, 1993, 74, 1. 
(44) Orcel, G.; Hench, L. J. Non-Cryst. Sol., 1986, 79, 177.

(45) Beurroies, I.; Ågren, P.; Bu1chel, G.; Rosenholm, J.B.; Amenitsch, H.; Denoyel, R.; Lindén, M. J. Phys. Chem. B, 2006, 110, 16254.

(46) Möller, K.; Kobler, J.; Bein, T. Adv. Funct. Mater., 2007, 17, 605.

(47) Sadasivan, S.; Fowler, C.E.; Khushalani, D.; Mann, S. Angew. Chem. Int. Ed., 2002, 41, 2151.

(48) Friman, R.; Backlund, S.; Hassan, O.; Alfredsson, V.; Lindén, M. Coll. Surf. A: Physicochem. Eng. Asp., 2006, 291, 148. 
Table 1. Evaluation of experimental techniques used in literature to perform time-resolved in-situ studies on mesostructured silica powders obtained by precipitation in solution. The number of + signs measures the suitability of the technique for in situ and/or time-resolved studies.

\begin{tabular}{|c|c|c|c|}
\hline Techniques & Output & In-situ* & Time-resolved** \\
\hline TEM & Micelle aggregates; Ordering & - & ++ \\
\hline SAXS & Shape of aggregates; Ordering & +++ & +++ \\
\hline EPR & $\begin{array}{l}\text { Organic/Inorganic interaction; } \\
\text { Micelle aggregates }\end{array}$ & $+(+)$ & +++ \\
\hline DLS & Apparent aggregate size & $+(+)$ & + \\
\hline Fluorescence & $\begin{array}{l}\text { Organic/Inorganic interaction; } \\
\text { Micelle aggregates }\end{array}$ & + & +++ \\
\hline \multirow{5}{*}{ NMR } & Surfactant mobility & ++ & ++ \\
\hline & Ordering; mesophase & + & ++ \\
\hline & Extent of hydrolysis/condensation & ++ & - \\
\hline & Hydrolysis & - & ++ \\
\hline & Mesophase growth & + & + \\
\hline FT-IR & Reactivity of inorganic species & + & +++ \\
\hline Raman & Reactivity of inorganic species & +++ & +++ \\
\hline
\end{tabular}

* Each + sign corresponds to one of the following criteria : 1) no external species introduced in the reacting medium (e.g. paramagnetic or fluorescence probes, etc...);2) no modification of chemical composition (e.g. dilution, use of $\mathrm{D}_{2} \mathrm{O}$, use of TMOS vs. TEOS, etc...); 3) no modification in the synthesis process (e.g. no stirring, smaller reaction volumes, etc...).

** The signs correspond to the characteristic measurement time of the related technique, $\mathrm{t}_{\mathrm{m}} ;+++$ : $0<\mathrm{t}_{\mathrm{m}}<10 \mathrm{~s} ;++$ : $10 \mathrm{~s}<\mathrm{t}_{\mathrm{m}}<1 \mathrm{~min} ;+: 1<\mathrm{t}_{\mathrm{m}}<10 \mathrm{~min} ;-: \mathrm{t}_{\mathrm{m}}>10 \mathrm{~min}$. 
Table 2. List of the systems under investigation.

\begin{tabular}{|c|c|c|c|c|c|c|c|}
\hline \multirow[t]{2}{*}{ System } & \multicolumn{4}{|c|}{ Molar Composition } & \multirow[t]{2}{*}{$\mathrm{C}_{\mathrm{Si}}(\mathrm{M})$} & \multirow[t]{2}{*}{$\mathrm{C}_{\mathrm{HCl}}(\mathrm{M})$} & \multirow[t]{2}{*}{$\mathrm{C}_{\mathrm{CTAB}}(\mathrm{M})$} \\
\hline & TEOS & CTAB & $\mathrm{HCl}$ & $\mathrm{H}_{2} \mathrm{O}$ & & & \\
\hline $\mathrm{A}$ & 1 & 0.12 & 9.2 & 130 & $4.310^{-1}$ & 3.9 & $5.0 \cdot 10^{-2}$ \\
\hline $\mathrm{B}$ & 1 & 0.12 & 9.2 & 200 & $2.810^{-1}$ & 2.5 & $3.3 \cdot 10^{-2}$ \\
\hline $\mathrm{C}$ & 1 & 0.12 & 49.5 & 700 & $0.810^{-1}$ & 3.9 & $9 \cdot 10^{-3}$ \\
\hline
\end{tabular}


Table 3. Raman bands of CTAB, Ethanol, TEOS and silica gel reported in lietrature.

\begin{tabular}{|c|c|c|}
\hline Species & Wavenumber $\left(\mathrm{cm}^{-1}\right)$ & Assignments \\
\hline \multirow[t]{2}{*}{$\mathrm{CTAB}^{38}$} & 763 & $\mathrm{NCH}$ rock. from $\mathrm{N}^{+}\left(\mathrm{CH}_{3}\right)_{3}$ \\
\hline & 1063 & $\mathrm{CC}$ stretch $+\mathrm{CH}_{2}$ wag. \\
\hline \multirow[t]{4}{*}{ Ethanol $^{37}$} & 436 & OC def. \\
\hline & 885 & CCO sym. Vibr. \\
\hline & 1055 & C-O sym. stretch. \\
\hline & 1095 & C-O asym. stretch. \\
\hline \multirow[t]{4}{*}{ TEOS $^{37}$} & 658 & $\mathrm{SiO}_{4}$ sym. strech. \\
\hline & 800 & $\mathrm{SiO}_{4}$ asym. strech. \\
\hline & 933 & C-C sym. strech. \\
\hline & 1095 & C-O asym. strech. \\
\hline \multirow{3}{*}{$\begin{array}{l}\text { TEOS-derived } \\
\text { oligomers }^{40}\end{array}$} & 600 & $\mathrm{SiO}_{4}$ sym. strech. in $\mathrm{Si}_{2} \mathrm{O}(\mathrm{OEt})_{6}$ \\
\hline & 576 & $\mathrm{SiO}_{4}$ sym. strech. in $\mathrm{Si}_{3} \mathrm{O}_{2}(\mathrm{OEt})_{8}$ \\
\hline & 534,554 & $\mathrm{SiO}_{4}$ sym. strech. in $\mathrm{Si}_{4} \mathrm{O}_{3}(\mathrm{OEt})_{10}$ \\
\hline \multirow[t]{4}{*}{ Silica gel ${ }^{40}$} & $\sim 600$ & $\mathrm{Si}(\mathrm{OSi})(\mathrm{OR})_{3}(\mathrm{R}=\mathrm{H}, \mathrm{Et})$ \\
\hline & $\sim 540$ & $\mathrm{Si}(\mathrm{OSi})_{2}(\mathrm{OR})_{2}(\mathrm{R}=\mathrm{H}, \mathrm{Et})$ \\
\hline & $\sim 495$ & $\mathrm{Si}(\mathrm{OSi})_{3}(\mathrm{OR})(\mathrm{R}=\mathrm{H}, \mathrm{Et})$ \\
\hline & 430 & $\mathrm{Si}(\mathrm{OSi})_{4}$ \\
\hline
\end{tabular}




\section{Captions for Figures}

Figure 1 : Scheme representing our time-resolved in-situ approach to study the formation of surfactant-templated silica powder.

Figure 2 : Raman spectra of $\mathrm{CTAB} / \mathrm{H}_{2} \mathrm{O}=0.12 / 200$ and $\mathrm{CTAB} / \mathrm{EtOH} / \mathrm{H}_{2} \mathrm{O}=0.12 / 4 / 200$ solutions $\left(\mathrm{C}_{\mathrm{HCl}}=2.5 \mathrm{M}\right)$.

Figure 3 : Time-resolved in-situ Raman spectra of (a, b) TEOS/ $\mathrm{H}_{2} \mathrm{O}$ (1:200) and (c, d) $\underline{\mathrm{CTAB}} / \mathrm{TEOS} / \mathrm{H}_{2} \mathrm{O}=0.12 / 1 / 200$ solutions corresponding to system $\mathrm{B}\left(\mathrm{C}_{\mathrm{HCl}}=2.5 \mathrm{M}\right)$. a) and c) Selected Raman spectra at different reaction times (TEOS addition sets $t=0$ ); $b$ ) and $d$ ) : Evolution as a function of time of Raman integrated intensities of $v(\mathrm{CCO})_{\mathrm{s}}$ at $885 \mathrm{~cm}^{-1}$ and $v_{\mathrm{s}}\left(\mathrm{SiO}_{4}\right)$ bands at $658 \mathrm{~cm}^{-1}$. Numbers from 1 to 5 in b), d) correspond to selected spectra shown, respectively, in a) and c). Pictures in d) show the reaction beaker after $5 \mathrm{~s}$ and $145 \mathrm{~s}$ from TEOS addition.

Figure 4 : Comparison of Raman peak intensity of ethanol $\left(885 \mathrm{~cm}^{-1}\right)$ as a function of time for systems A, B and C. Expected values for complete hydrolysis are indicated for each system.

Figure 5: Time-resolved XRD patterns showing the formation of SBA-3 for systems A-C. See text for details. A data accumulation time of $10 \mathrm{~s}$ per frame was used. Data were not background corrected.

Figure 6 : Surface plots corresponding to the time-resolved XRD patterns for systems A-C. Data were background corrected.

Figure 7 : Time-evolution of the position of the (10) reflection of the 2D hexagonal SBA-3 phase for systems A-C.

Figure 8 : Time-evolution of the integrated intensity of the (10) reflection of the 2D hexagonal SBA3 phase for systems A-C. 
Figure 9 : Time-evolution of the full-width-at-half-maximum, FWHM, of the respective (10) reflections of the 2D hexagonal SBA-3 phase for systems A-C. 


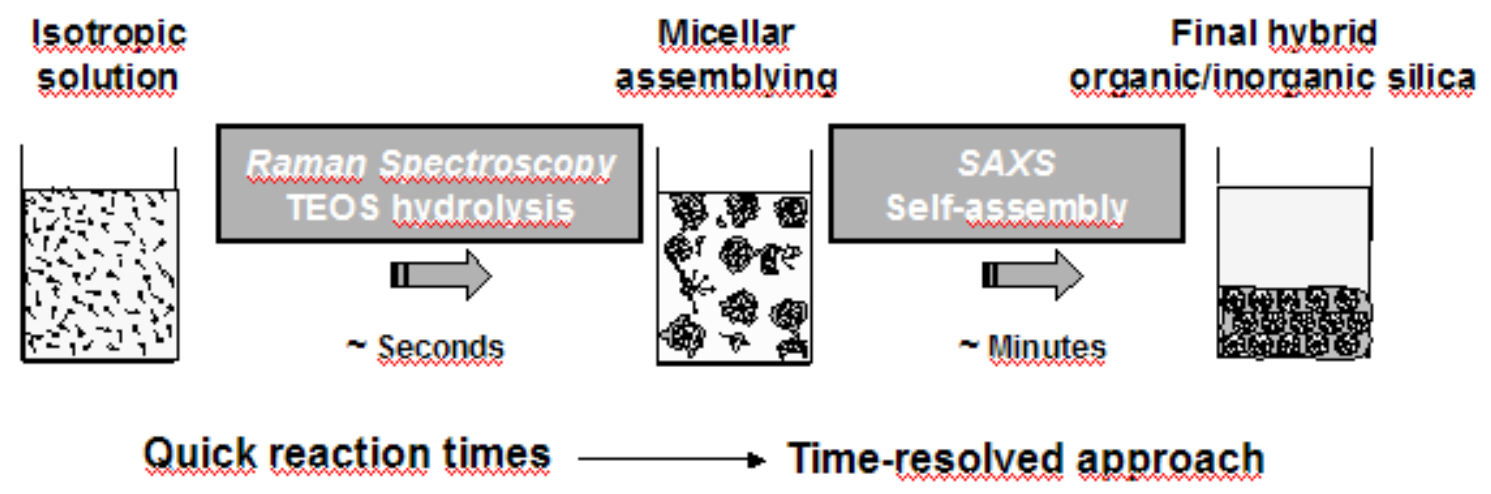

Figure 1 




Figure 2 


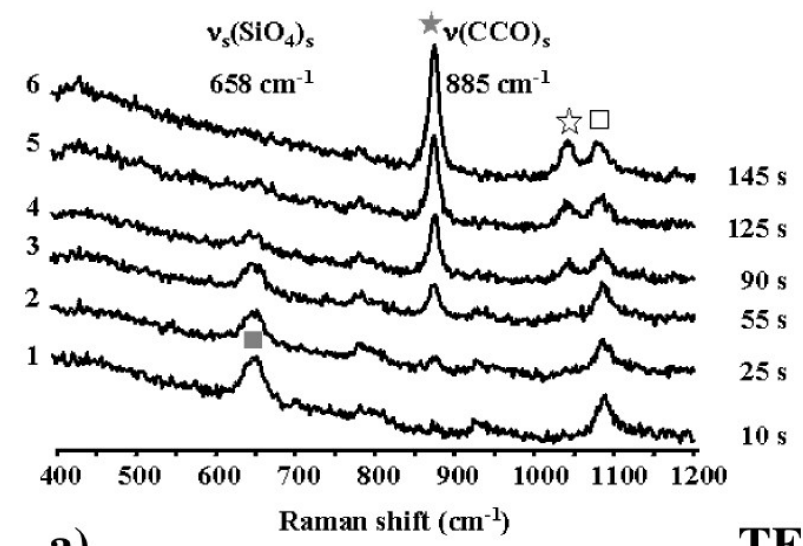

a)





b)

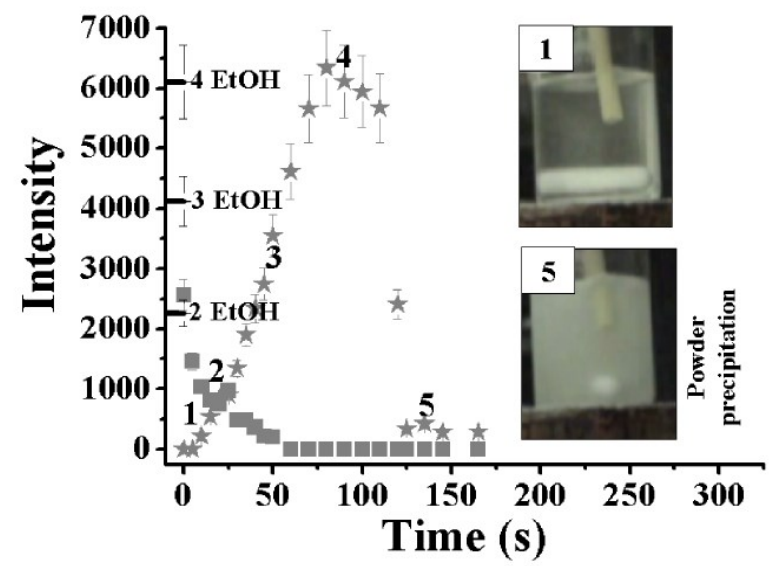

c)

TEOS/CTAB/HCI/ $/ \mathrm{H}_{2} \mathrm{O}$

d)

Figure 3 


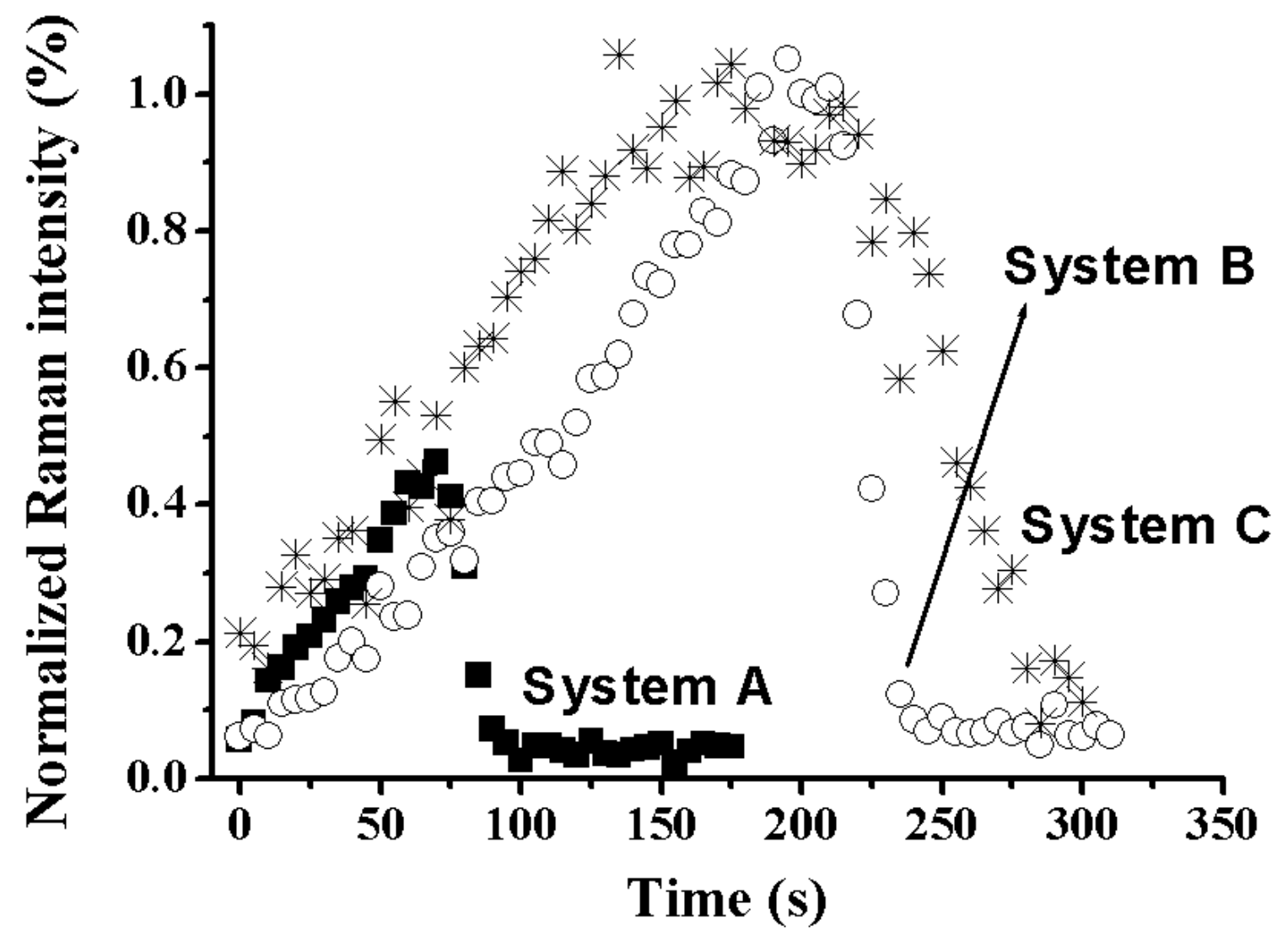

Figure 4 

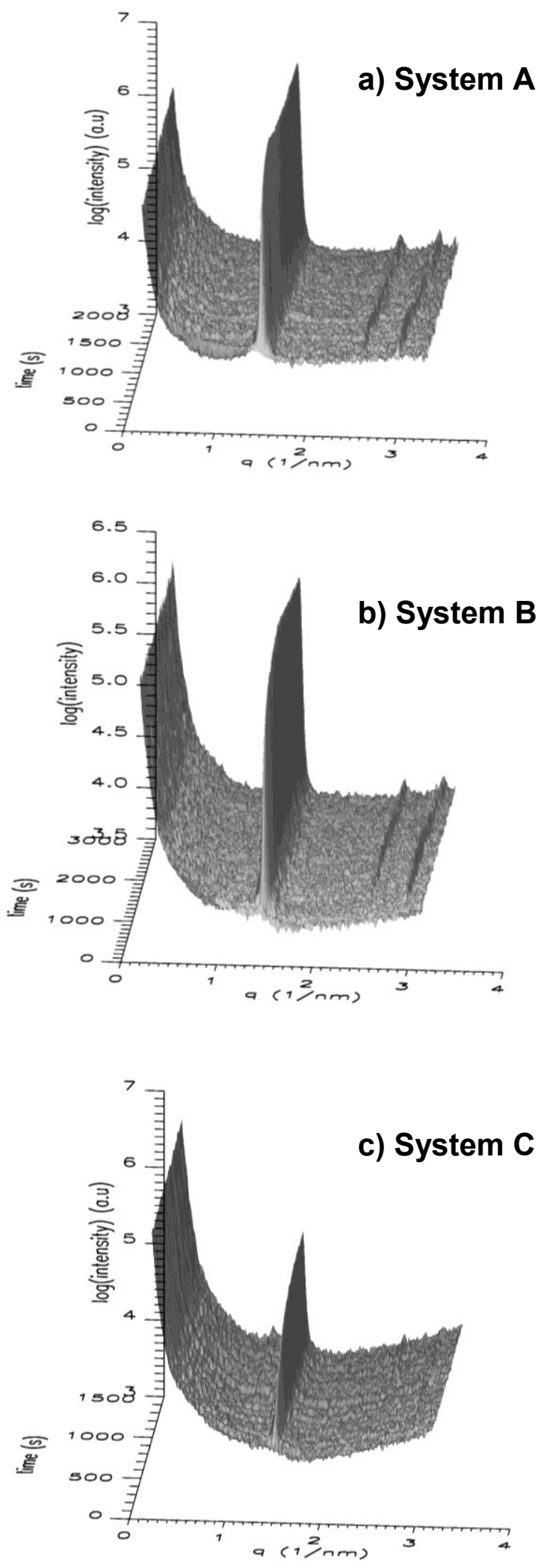

Figure 5 

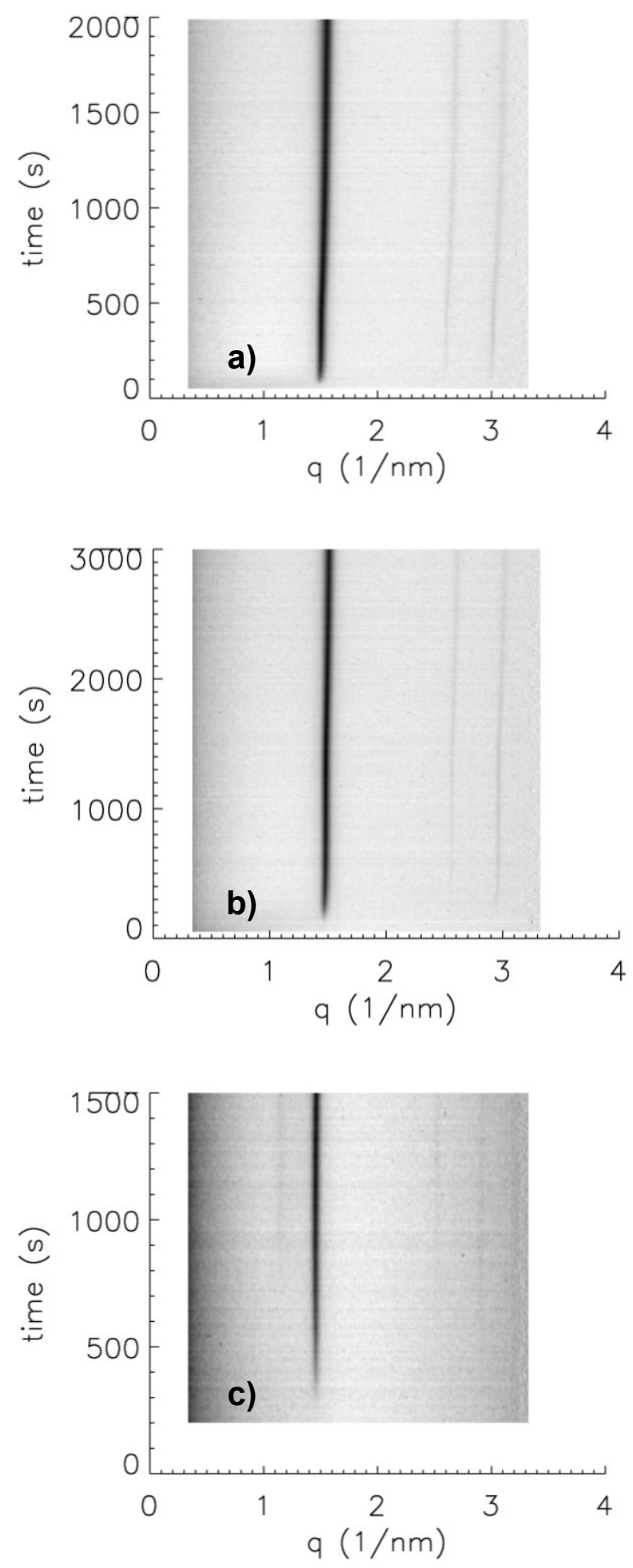

Figure 6 


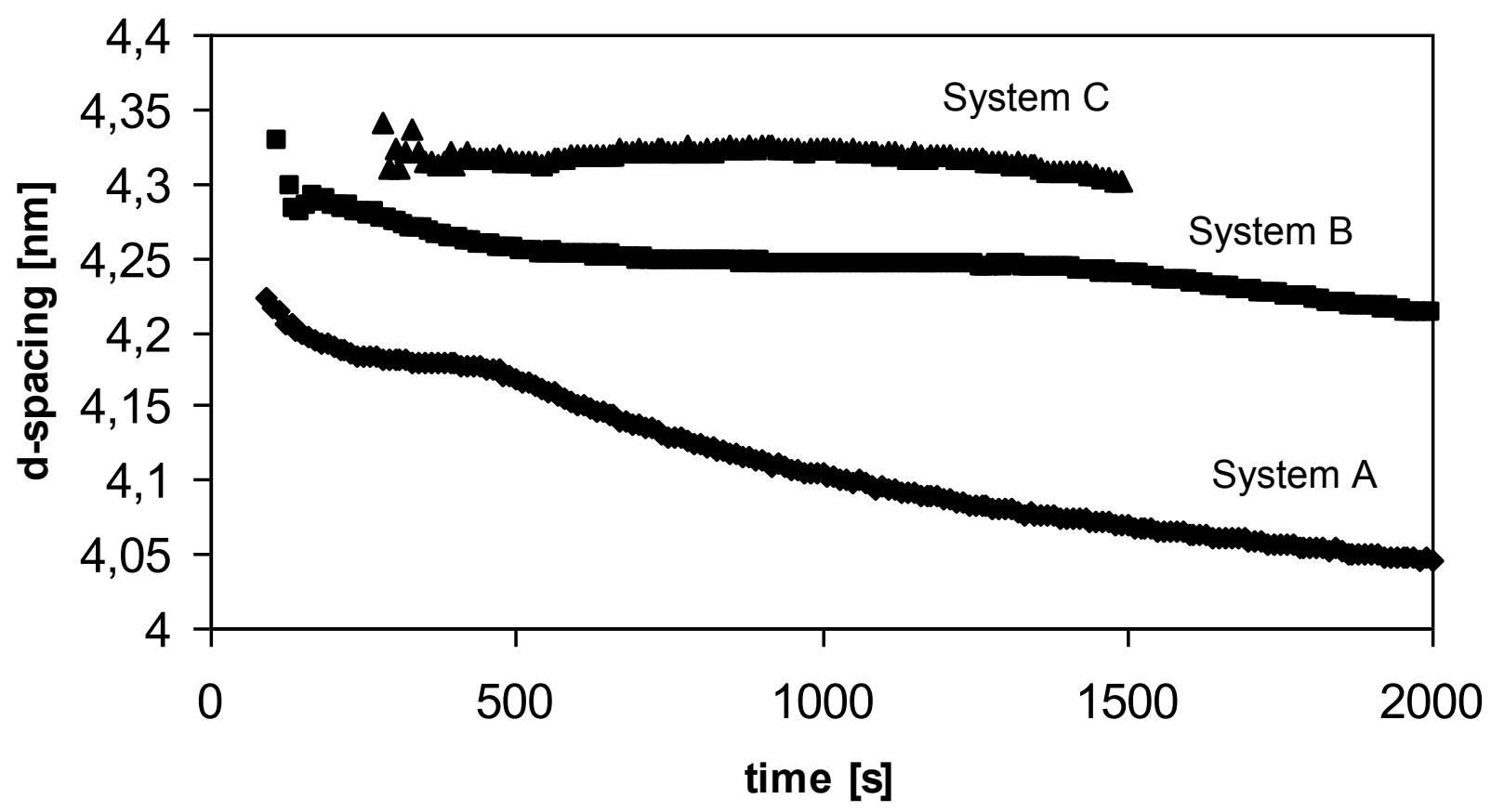

Figure 7 


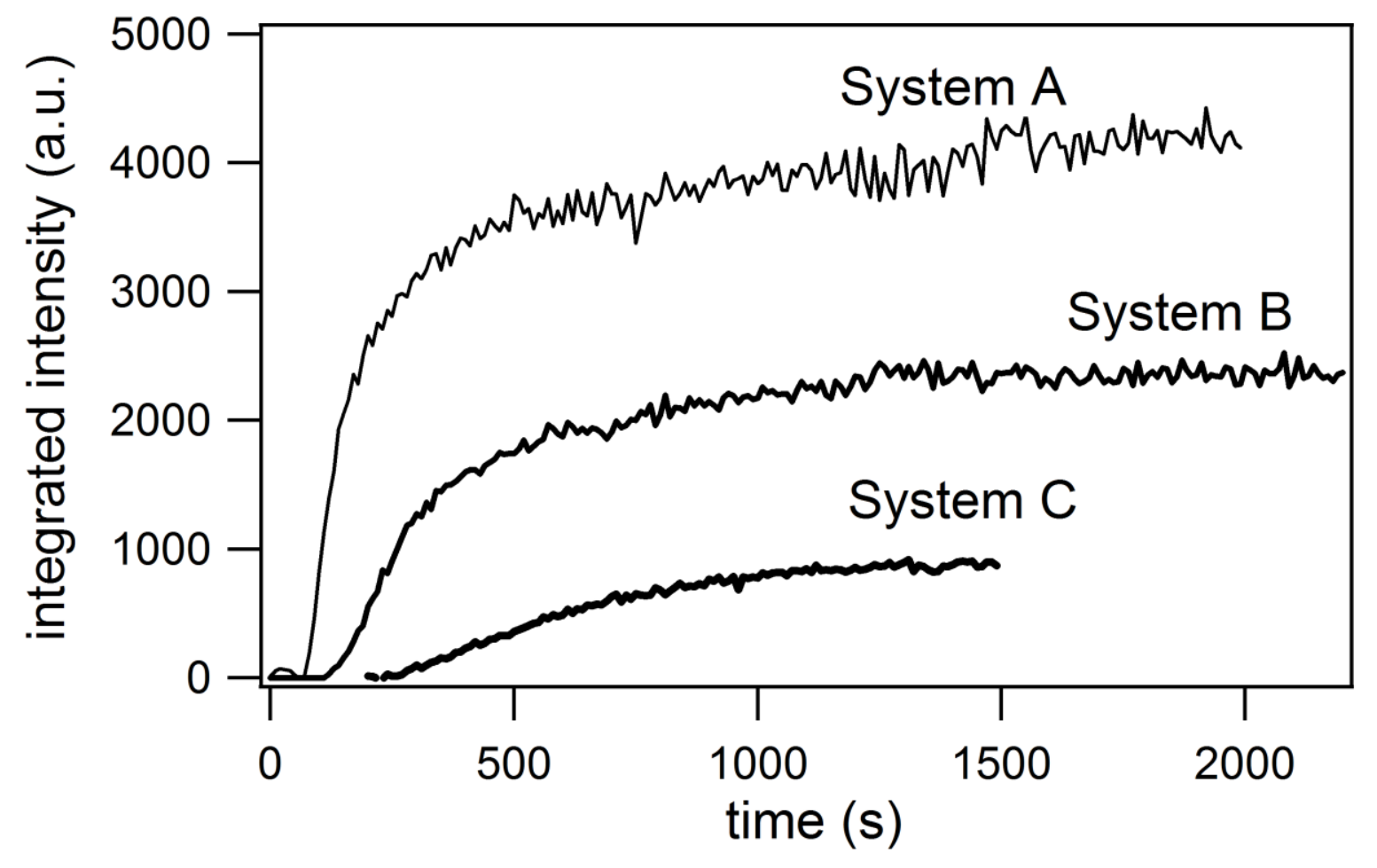

Figure 8 


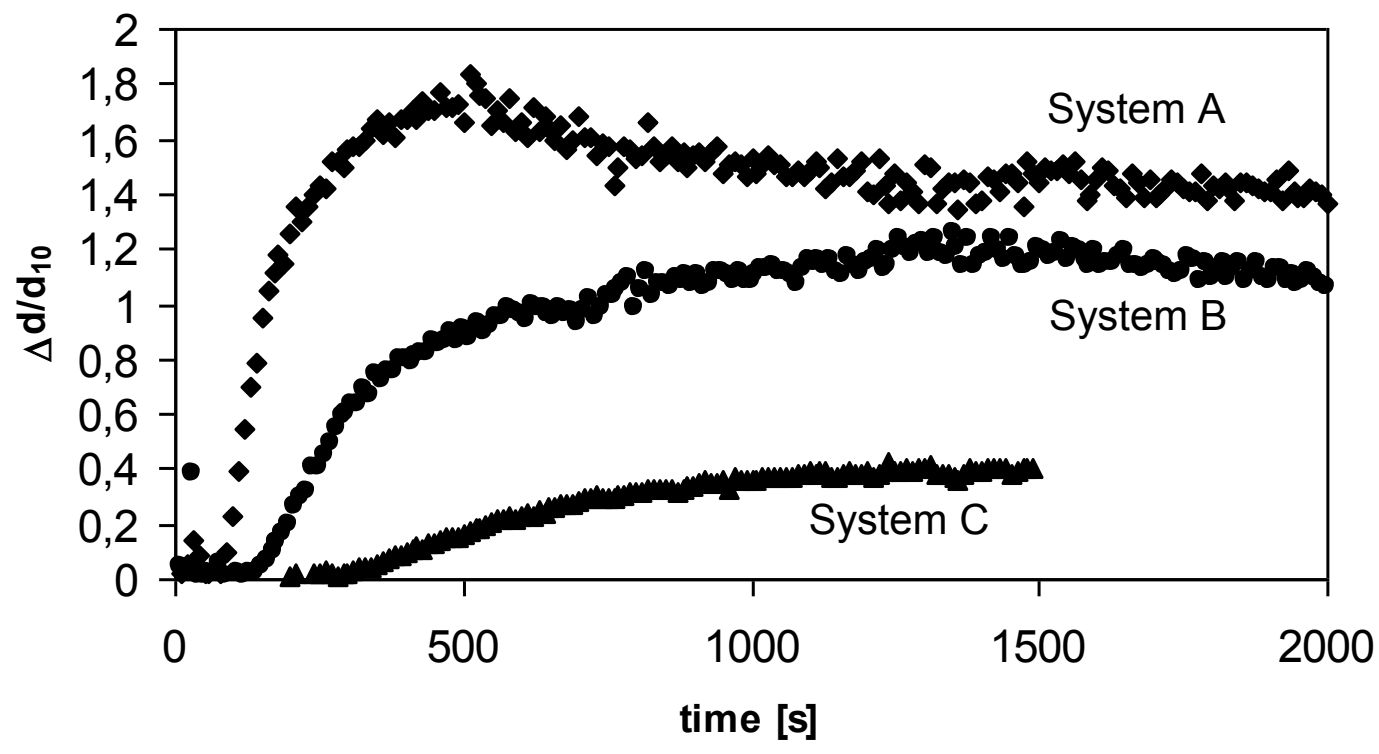

Figure 9 